\title{
Ceaselessly Exploring, Arriving Where We Started and Knowing It for the First Time
}

\author{
Richard Davies ${ }^{1}$
}

Published online: 18 March 2016

(C) The Author(s) 2016. This article is published with open access at Springerlink.com

\begin{abstract}
In this paper I explore the implications of the increasing social and sociable uses of new, mobile internet associated technologies (MIATs) for online learning. In particular I focus on tablet computers as at the vanguard of this shift. Drawing on discourses of technobiophilia and phatic communion, the propositions explored in this paper are that: (a) that internet associated technologies have been shaped by and reflect the ways in which humans engage with objects and each other in the physical world, (b) that of particular significance for MIATs are frequent small scale social interactions between users, and (c) that a more detailed consideration of these affordances would enhance online learning. I develop this account by considering the potential role of relationships for supporting the development of socially cohesive learning groups and the enhancement of online learning. In particular I focus on the need for partiality within a learning group and mechanisms for managing conflict. I conclude by offering two broad principles for a more sociable online learning experience.
\end{abstract}

Keywords Online learning - Mobile technologies · Phatic communion ·

Technobiophilia $\cdot$ Relationships

\section{Introduction}

This paper explores the implications of the increasing social and sociable uses of new, mobile internet associated technologies (MIATs) for online learning. In particular I focus on tablet computers as at the vanguard of this shift. The last 15 years has seen a significant change in mobile technologies (hardware and software) supporting social interaction, and

Richard Davies

Rid11@aber.ac.uk

1 School of Education and Lifelong Learning, Aberystwyth University, Penglais Campus,

Aberystwyth, Ceredigion SY23 3UU, UK 
offering tools to enhance online learning. Facebook (established 2004) and Twitter (established 2006) as well as free blogging sites (for example, Wordpress established 2003) have seen extensive growth in developing social interactions, especially through mobile devices. Online (distance) ${ }^{1}$ learning has, in my experience, also been transformed. Fifteen years ago, bulletin boards allowed for information exchange between tutors and students, and some asynchronous communication. Today, it is characterised by more synchronous communication, online lectures, and conversation. What is more, it utilises many of the same technologies students use in their personal and professional lives. Online learning is no longer a strange space unique to university courses, but an extension of the familiar. Further, and only more recently, has the relational dimension of these new approaches come to the fore, changing from a focus on internet-associated technologies for information exchange to a focus on both information and relational interchange.

There is still relatively little published work on the use of MIATs in teaching and learning (see Berge and Muilenburg 2012, especially O'Loughlin et al. 2012, for the analysis of a small scale study of Australian academics; also Corbeil and Valdes-Corbeil 2007; Hamm et al. 2014). Although it has to been noted that mobile technology use is rife, that students are becoming 'increasingly teachered to their technology' (Rideout et al. 2010) and that tablet computer purchases in the UK rose to slightly over 12 million in 2014 (Statista 2015). There are, of course, broader institutional level drivers for the development of online learning (see Bramble and Panda 2008, for a US based analysis), both in terms of extending reach through online learning (delivering more programmes), and by utilising the investment in technology by requiring campus based programmes to have an online component (see Davies and Eynon 2013). This recent review of online learning use suggests that there are few (if any) academic staff involved in teaching in higher education who are not using virtual learning environments. Higher education is being pushed into greater utilisation of online learning by student expectation and the rise of competitor models such as large open courses (see Yuan and Powell 2013). At the same time there are indications that students on campus based programmes resent the use of technology to replace face-to-face interactions (see Kandiko and Mawer 2013). Further, there are a number of studies which identify relationships between students and between students and tutors as significant for students participating in online programmes (see for example, Moore et al. 2011; Garrison et al. 2000; Garrison and Kanuka 2008; Means et al. 2010; Wu et al. 2010; Sharpe et al. 2006; Gilbert et al. 2007; Chatti and Jarke 2007). In this paper I am primarily concerned with distance learning (non-campus based) programmes. However, as the use of virtual learning environments increases in campus based programmes, alongside a reduction in face-to-face interactions between members of the same learning group, a concern with both relational and information exchange will become significant to both distance and campus based programmes.

The focus on the humanising of the web (Oinas-Kukkonen and Oinas-Kukkonen 2013), of a concern with phatic communion using internet-associated technologies (Wang et al. 2011, 2012), the language of technobiophilia (Thomas 2013), and the more ubiquitous 'web 2.0' all emphasize a focus on exchange, user generated content and more relationally informed modes of engagement. This is not to claim that the internet did not previously have a social dimension. As Tim Berners-Lee noted 'I designed [the web] for a social effect— to help people work together-and not as a technical toy' (quoted in Thomas 2013: 7). Rather, as Oinas-Kukkonen and Oinas-Kukkonen (2013: 7) have observed, we are

1 In this paper I have used the term 'online learning' to cover both distance learning programmes and
programmes where for significant periods the relationships between students are mediated by technology. 
seeing a movement 'in which people are finally considered as more important than technology'. Educationally, these broad discourses about internet use enable a renewed 'more sociable' framing, modelling, critique and development of our online teaching practices.

The propositions explored in this paper are that: (a) that internet associated technologies have been shaped by and reflect the ways in which humans engage with objects and each other in the physical world, (b) that of particular significance for MIATs are frequent small scale social interactions between users, and (c) that a more detailed consideration of these affordances would enhance online learning. It is worth noting that this approach is not a neutral description of the state of online learning. As Carey (1992: 32) points out '[o]ur models of communication...create what we disingenuously pretend they merely describe'. The process of a particular description and critique creates new approaches to engagement with MIATs and online learning. Further, I recognise that others have raised significant issues with technology mediated interaction (see for example, Ellison and Boyd 2013; Galloway 2012). Whilst programmes delivered online have certain advantages in terms of flexibility and easy access for those unable to attend a physical campus, such advantages may well also entail disadvantages to students. In this paper I am not seeking to defend online learning over face-to-face learning, but rather to: (a) foreground the relational aspects of structured higher education, and (b) the emerging possibilities for MIATs to support improving this aspect for online students.

I begin to address this by briefly reviewing Thomas and Wang et al.'s accounts of technobiophilia and phatic communion respectively. The purpose is to provide a background discourse for considering the development of relationships between students participating in online programmes. In "The Phatic Trinity: Hardware-Software-Users" and "Developing the Phatic and Relational Aspects of Online Learning" sections I develop this account by considering the particular affordances of MIATs and the potential role of relationships for supporting the development of socially cohesive learning groups. In particular I focus on the need for partiality and mechanisms for managing conflict. I conclude by offering two broad principles for a more sociable online learning experience.

\section{Framing Sociable Online Interactions}

Whereas 'phatic communion', that is the tittle tattle and 'set pieces' of everyday communication, draws attention to the social purposes and possibilities of internet associated technologies; technobiophilia is concerned with the deeper ways in which human agents conceptualise the web, cyberspace and internet. Thomas notes early on that:

...some of the features we so value in the natural world can also be found online; indeed, our subconscious has already imprinted nature onto cyberspace. (Thomas 2013: 4)

A small selection of the most ubiquitous examples includes '...bug, cloud, mouse, river, root, spider, stream, surf, swarm, tail, trail, tree, virus, web, worm' (Thomas 2013: 4). The coming of cyberspace has, Thomas notes, 'presented us with a new landscape which while unarguably virtual, is also deeply resonant of the physical' (Thomas 2013: 11).

From consideration of these verbal clues, Thomas explores two aspects. The first is that these metaphors have the power to allow alternative interpretations. For example, 'the cloud', a series of earthbound computers and storage allows, once schematised as 'a cloud', for other possible, and potentially more practically useful interpretations. The use of the 
term 'cloud' draws attention away from the physicality of the hardware itself, and rather focuses on its omnipresent character. The second, and most significant, is applying E.O. Wilson's concept of 'biophilia' to technology as technobiophilia 'the innate tendency to focus on life and lifelike processes as they appear in technology' (Thomas 2013: 12). For Thomas, Wilson's thesis deals with this use of metaphors from nature in online environments:

I started out with a question as to why we have brought nature with us into the online world and the answer, it seems, lies in an experience with very primordial roots. (Thomas 2013: 12)

Thomas, utilising Wilson, goes further than suggesting that there is merely a verbal affinity between the physical, especially the natural, and the virtual. The 'landscape' of the virtual is formed in the image of the natural world, and it is not surprising that we build in it 'structures' and 'platforms', that reflect our 'natural' experiences of 'life and life-like processes'. There are two implications of technobiophilia for online learning. Firstly, we utilise the same concepts, for example, classrooms, discussion, seminars in the virtual as well as the physical learning environments. The virtual learning environment and our conceptualisation of it is made in the image of its physical counterpart. We are constructing 'virtual' environments which are, as Thomas puts it, 'deeply resonant of the physical'. Secondly, technobiophilia draws attention to a tendency for agents to conceptualise their activities in similar ways in virtual and physical environments. Teaching and learning in both online and campus contexts draw on the same general discourse of learning environments, human capacities and dispositions. Our activity, online and face-to-face, can be expressed utilising the same concepts, part of this is the way we conceive of the development and maintenance of appropriate relationships between learners.

Wang et al. $(2011,2012)$ are less concerned with the conceptualization of the virtual world, but its role in supporting relationship building and enhancing interpersonal communication. They deal with at least two ways in which these relational aspects of communication are important. The first is the importance of general tittle-tattle. Quoting Malinowski they note the origins of phatic communion in linguistics as identifying both the 'aimless...uninteresting...even irrelevant' and yet 'part of the process of fulfilling our intrinsically human needs for social cohesiveness and mutual recognition' (Wang et al. 2011: 48). The second is the role of 'set pieces' in our conversation. Such set pieces support the civility of our communications, allowing not only recognition, but also enabling us to convey good manners in our interactions. Drawing on Laver (see also Laver 1975) they call attention to three functions of phatic communion: propitiatory, exploratory and initiatory (ibid: 48).

The propitiatory function defuses possible attributions of hostility through silence. Simultaneously, phatic opening phases also serve an exploratory function in the tentative nature of such exchanges. The initiatory function serves to get the interaction under way [and i]n closing sequences...may mitigate a possible sense of rejection and help consolidate a relationship... (ibid: 47)

Phatic communion is, therefore, at least in part about the fulfilment of social rituals and expression of good manners in an age of increasing informality (see for example, Wouters 2011; Stohr 2012). It supports the maintenance of social relationships in culturally appropriate ways, though prescribed interactions (for example, 'how are you today?'), as well as the general tittle-tattle of the everyday, expressive of casual conversations between 
individuals. As my later discussion will claim, Whilst learning requires a certain level of discipline in thought and communication, the phatic aspects of communication express the necessary manners of effective relationships between peers within a learning community.

Wang et al. are primarily interested in those 'internet-associated technologies [which are] increasingly used and...even created especially for social purposes' (Wang et al. 2012: 44). They focus on 'phatic technologies', which they summarize as those whose 'primary purpose or use is to establish, develop and maintain human relationships' (ibid: 46). These technologies allow users to fulfil 'personal interactive goals' (ibid: 44) and these goals are 'the social basis of a community' (ibid: 44). Part of Wang et al's argument is that you cannot disassociate the phatic aspects of the technology from the purposes of users and their particular context.

Although online teaching and learning is not a distinctive phatic activity, and the analysis in this paper differs from Wang et al.'s focus, nevertheless teaching and learning usually require some form of relational aspect, and, historically, an aspect of university life has been premised on extended relationships between students, and students and tutors. For example, Garrison et al. (2000) noted the importance of 'social presence' for the development of critical inquiry in computer mediated courses, though as Kreijnsa et al. (2003) discuss there are dangers in assuming that a suitable environment for relationships is sufficient. They argue for a greater consideration of the ways that groups, and learning groups, develop. A detailed analysis is beyond the scope of this paper, but represents a timely reminder that just enhancing the relational aspects of online programmes will not necessarily improve the learning that occurs.

Wang et al. argue that the relational aspects of online communication have not received sufficient attention in shaping our understanding of both the role and the importance of recent technological developments. They identify two aspects. The first is that phatic technologies emerge from an interaction between 'technologies' and users:

...the phatic use of technology is reflexively determined by the relationship between the producers, the users and non-users, and the phatic technology. At the heart of the relationship lies interpretive flexibility. (Wang et al. 2011: 47, original emphasis)

Whilst some, such as twitter and facebook, have relationship development as a primary raison d'etre, others develop phatic aspects in response to user engagement (and the nonengagement of non-users), for example, comments and reviews on ebay and Youtube. Yet other 'blank' spaces such as wikispaces or wordpress have been used to develop online communities. Thus, although we can point to technologies whose purpose is distinctly phatic; we are more frequently identifying the way that technology is being used and adapted to support particular types of relationships. The second is that when referring to technology we are referring both to hardware and software; the physical devices and the platforms which we utilise 'though' those devices. Wang et al.'s development of the importance of the phatic rightly reshapes how we can think about the use of technology.

\section{The Phatic Trinity: Hardware-Software-Users}

As Wang et al. point out there is at the heart of phatic consideration of MIATs a trinity of the technology, hardware and software, and the users. It is worth developing this trinity in relation to online learning. In part to counter a view that the software-distinctively phatic communion enhancing platforms - are the most important aspects of this shift towards more sociable technologies. 
As noted in the introduction, in this paper I am focusing on mobile technologies, primarily tablets and the apps that animate them. My argument is that mobile devices offer a different type of relationship with the user than that afforded by 'static' computers, especially through their tactility, portability and transparency. The first two are, I hope, relatively self explanatory. Steve Jobs as part of the publicity for the release of the iPhone in 2007 pointed out:

We are all born with the ultimate pointing device-our fingers—and iPhone uses them to create the most revolutionary user interface since the mouse. (Apple 2007)

Tablet computers have increasingly utilised this tactile potential through a range of multigesture commands, telemetry functions and easy navigation between different applications/ screens. This is supported by the portability of tablets-they are relatively light and well balanced for ease of handling. Along with long battery life, these feature make for a mobile device. Ling (2012) argues that '[t]he mobile phone has become important mainly because it facilitates the mundane aspects of our lives...' and the same can be said, though perhaps for a more limited number of individuals, of tablet computers.

The issue of transparency is perhaps less clear. In a discussion of the use by the visually impaired person of the use of a 'cane', Hodgkin (1985) distinguishes between the 'proximal' and the 'distal'. In using the 'cane' the interaction between the person and the 'cane' is in the hand; that is where the sensation is. However, as Hodgkin points out if the individual focusses on their hand and the sensation, that is the proximal, they are inhibited from feeling the end of the 'cane', that is the distal. A focus on the proximal undermines the purpose of the 'cane', as the visually impaired person actually seeks to feel the distal. This distinction between a focus on the proximal and the distal is helpful in reflecting on the experience of using tablet computers. We talk of watching TV, of skyping, checking email, etc. all by engaging with the tablet, but what we are aware not of the tablet itself, but what it becomes. The distal is the focus, and design of the tablet enhances its transparency. This reduces the barriers between users, we experience each other more immediately, although still mediated by the technology used.

The point here is, firstly that tablet computers offer a different kind of experience, offering the opportunity for frequent use and enabling the easy utilisation of a range of applications. Secondly, I am claiming that such computers emphasise the distal-the focus of the engagement as opposed to the proximal, the tablet itself. In the case of direct engagement with other users this heightens the immediacy of the contact, and the relational aspect of the engagement.

Briefly, I also want to consider the changing nature of users, often these debates focus on students through Prensky's lens of digital immigrants and natives' or his critics (see Prensky 2001). Whilst the computer habits of students are relevant, here I want to focus on the changing capability of online tutors. Whereas 15 years ago the majority of tutors involved in online learning were specialists or early adopters (often supported by specialist technical support), the situation has changed with almost all academic staff being involved in some type of online learning (see Davies and Eynon 2013). The facilitators and designers of online learning are progressively drawing not so much on a discourse of specialist online learning, but rather on a discourse and experience of online interaction garnered in their everyday personal and professional life. These include a significant engagement in the kinds of phatic technologies identified Wang et al.

The trinity of hardware-software-user has, I am claiming, shifted and at the heart of this shift is a greater emphasis on social engagement supported by, and influencing, the technology available and its affordances. In considering the implications for online 
learning, it is not just the software that is critical, but the ways in which users can and do engage in the virtual world. If Thomas (and Wilson) is correct then this online engagement, and the environments within which it occurs, is reflective of the offline world, and the styles of learning and teaching practiced there.

\section{Developing the Phatic and Relational Aspects of Online Learning}

I have briefly outlined that it seems reasonable, in the type of structured higher education under consideration, that relationships are important in supporting learning whether conducted in virtual or physical environments. I take it though that this is ultimately an empirical rather than philosophical matter. To be clear I am not claiming that such relationships are necessary for learning to occur. I can learn from a book or television programme with no relationships with others. I can learn in the context of a group with whom the relationships are largely negative, or learn as an individual in a group context. In many ways this 'individual in the group context' represents my early experiences of online courses. We could run asynchronous discussion groups and students would, if it was a course requirement, complete what was required of them. Rarely did these discussion groups form a conversation about the topic, students rarely did more than the minimum, and there were no indications of engagement between students. This changed markedly with the introduction of fortnightly small group webinars. These synchronous, video and audio engagements improved the quality of the discussion on the discussion board. It is an empirically matter as to the precise contribution of relationships to learning, but as a practitioner I am largely convinced of the value of relationships for improving engagement between students on online courses, as I am of their importance in face-to-face teaching.

If relationships are important in online learning there are two types of relationships of concern: peer relations between students and the relationships between the tutors and students. The former including aspects of developing individual students into a learning group, and development of the relational climate for effective collaborative learning and it is on these that I focus. It is, however, tutors who set the context for the relationships and offer mechanisms within the programme by which such relationships can be enhanced. In this section I set out some of the key issue that tutors might want to pursue in terms of developing a more sociable environment for online learning. In doing so I am seeking to defend a decision to consider the phatic aspects of communication in relationship to technobiophilia and the properties of MIATs. Whilst the focus on 'phatic communion' as an aspect of socio-linguistics, and more specifically the rise of applications supporting phatic interaction, is helpful in focussing attention on the relational aspects of online activities, it cannot be separated from the two other elements of the trinity identified; namely the hardware and users utilisation of the available technologies. In our case this includes both students users and tutor users. The discussion sits within a context in which the language of our online environment is articulated in terms of the physical world-both in general (as indicated by Thomas) and in particular in terms of our conceptualisation of online learning spaces.

Group development theories (for example, Tuckman 1965; Tuckman and Jensen 1977) model a path towards increasing social cohesion, in which individuals identify more closely with a group and show partiality towards other group members. Further they identify conflict as both a distinctive phase of group formation, and also an ongoing issue with which groups need to deal. Just as partiality affirms the group's cohesion, internal 
conflict erodes it. Two of the uses of phatic communion is that it provides a means of developing and affirming such partiality and of providing the relational context within which conflict can be well managed. That is not to say that the phatic aspects of communication will resolve conflict; such conflict may be based on significant, and irreconcilable differences of opinion. Rather that underpinning tittle-tattle and social 'set pieces' offer a context within which conflicts can be dealt with and accommodations reached.

So, in the early stages of relationship building, phatic exchanges-the basic, prescripted interactions of everyday life-provide the context for developing connections between individuals. Later, it also provides the medium through which 'in group' identities can be encoded. As Laver points out such phatic aspects of communication are essential parts of the maintenance of relationships and minimisation of unnecessary disagreement. This latter role is of some significance in programmes of study in which academic debate and disagreement is an essential component. There is a delicate line to be walked between reasonable and rigorous debate and unnecessarily offending others. The phatic aspects of communication allow such a balancing act to be achieved by students and by tutors. Online programmes that focus on task completion and asynchronous exchanges tend to leave little space for the phatic aspects of communication between individuals, but, following Karel et al. (2003), simply provide such space is not enough. There need to be regular opportunities for these to be expressed within the everyday activity of the programme and within particular learning tasks (when academic disagreement is more likely to occur).

Whilst we ought to seek to reduce unnecessary conflict, we also ought to provide opportunity to support the internal cohesion of the group - the development of partiality towards peers. Kolodny (2010) offers a critique of the development and legitimation of partiality in relationships. As part of his analysis he claims that the character of a particular relationship reflects the character of the episodes of interaction that compose that relationship. As well as the character of the particular episodes he argues that the character of a relationship reflects the diversity of different types of episodes of interaction between the individuals involved, and the frequency of those interactions. So, for example, relationships with close family are often composed of frequent episodes of diverse kinds reflective of the social, normative scripts of family relations. Where episodes diverge from reasonable interpretations of this socially agreed script, these are deemed to be unfortunately, tragic and perhaps deserving of censure. There is, however, an interplay between the socially expected form of a particular type of relationships between persons, and the ways in which the individuals involved and the particular experiences they have of interacting with each other, This interpretive flexibility gives a unique 'flavour' to that relationship. It is this distinct flavour that expresses the fact that this is not a relationship in general, but a relationship between particular people. In our example, family relationships share commonalities and yet are each unique.

In the context of any learning group we seek relationships which reflect the normal expectations of relationships between peers who are learning together as part of a class (or course of study) but also over time the relationships that emerge will be distinctive to this particular learning group. Individuals are not just studying the same subject; these relationships bind the individuals to this group. Such partiality to others allows the kinds of active debate and disagreement essential to academic study as well as grounding an expectation of support during collaborative tasks. Part of this movement results from a negotiation of the 'personal interaction goals' of the individual students (to draw on Wang et al.), on the tutor shaped environment with opportunities for students to express the phatic aspects of communication. There is in principle here no difference to face-to-face teaching 
and learning, for example, we recognise the need for periods of phatic exchange between students at the beginning and end of lectures, and often during long teaching sessions.

Kolodny's two further features are the diversity of the different episodes and their frequency. Which again reflect face-to-face interactions. We recognise the need of a learning group to experience additional time together as part of the induction process and for regular opportunities for learning groups to meet. We are concerned about those who have poor attendance not merely because they are missing teaching, but because they are becoming disengaged from their group. As universities we offer a diverse range of activities for students to interact with each other-increasing the diversity of the nature of different episodes that form peers' relationships with each other. The difficulty has been to develop such opportunities for distance learning students. Wang et al's review of phatic technologies gives us a starting point, a range of technologies whose primary purpose is to support and develop relationships. Facebook, Twitter, Instagram and other technologies have already been utilised for online learning. This offers a starting point to review and develop opportunities for increasing the frequency of interaction between students for minimal additional effort for them. Further, this concern with relationships will ensure that virtual learning environments are not chosen with an unnecessarily narrow focus on just supporting tasks, but also take into account the development of relationships between peers.

Within the context of a broader more long term set of relationships within the learning group there are moments of tension. In higher education debate, discussion and disagreement are essential to the learning that is occurring, but also collaborative learning activities generate the possibility of disagreement and conflict. The development of opportunities to express the set pieces of phatic communion, as identified by Laver, is one way to minimise the significance, and negative consequences, of such disagreement and conflict. The good management of inter-student relationships is foregrounded by this discussion on the phatic affordances of MIATs. What might this entail? Most notable is the recognition of mechanisms that not only allow for the fulfillment of tasks, but also other channels for students to engage in the broader tittle-tattle that supports a good mannered discussion and completion of those tasks. Such channels might be through extending the period online, for example, opening up an online webinar 30 min early in order for students to chat before the seminar, or utilising emoticons for students to express their feelings about the interactions, or supporting students to use video group conversations alongside the platforms being used for the collaborative tasks. In doing so students are able to recognise others and be recognised as member of this learning group and draw on the social cohesion they share.

In this section I have been seeking to 'put some flesh' on the bones of an account of online learning which occurs in an environment redolent of the physical, expressed in similar concepts, and one which supports the relational needs of students on a programme of study. In conclusion I spell out in brief summary two key points for the development of a more sociable approach to online learning utilising MIATs.

\section{A Future Sociable MIAT Mediated Learning?}

In this paper I have been arguing for a renewed concern with the contribution of relationships to online learning, in particular a focus on phatic aspects of communication. I have argued further that there are specific characteristics of MIATs that support such a 
focus on phatic communion between students. These include the easy transfer between applications, many of which encourage interactions between students, and a portability which enables frequent, low effort interactions of a phatic kind. Further, I have argued that MIATs become 'transparent' and offer a different, less intrusive, mediation between users. The discussion has also been framed in reference to technobiophilia; that our virtual environments and the ways we act within them are informed and shaped by teaching and learning in the physical environment.

Such technologies allow a flexible interaction between users, allowing them to pursue their 'personal interaction goals' within the context of socially expected relationships between students in a learning group. I have been arguing that tutors can utilise these technologies (hardware and software) to enhance the social cohesion of learning groups and to minimise the negative consequences of conflict emerging from collaborative student learning activities. Two key principles emerge. The first is that tutors ought to take seriously the need for students to engage in the tittle-tattle of everyday conversation and that for online students this needs to be facilitated by academic staff. I have suggested that this might include utilising phatic technologies to encourage low effort interactions on a regular basis. It might also include utilising teaching approaches, such as webinars, that allow time for students to chat to each other. The second is that tutors should support approaches to online collaborative working that encourage students to recognise each other as persons and members of the same learning group. Such approaches allow students to utilise phatic 'set pieces' which contribute to well managed disagreement and debate. These platforms are readily available to staff and students. Rather than creating new environments, the matter is one of repurposing those that we already have.

Open Access This article is distributed under the terms of the Creative Commons Attribution 4.0 International License (http://creativecommons.org/licenses/by/4.0/), which permits unrestricted use, distribution, and reproduction in any medium, provided you give appropriate credit to the original author(s) and the source, provide a link to the Creative Commons license, and indicate if changes were made.

\section{References}

Apple. 2007. Apple Reinvents the Phone with iPhone. Available from https://www.apple.com/pr/library/ 2007/01/09Apple-Reinvents-the-Phone-with-iPhone.html. Accessed 12 April 2015.

Berge, Z.L., and L. Muilenburg (eds.). 2012. Handbook of mobile learning. New York: Routledge.

Bramble, W.J., and S. Panda. 2008. Economics of distance and online learning: Theory, practice and research. New York: Routledge.

Carey, J.W. 1992. Communications as culture: Essays in media and society. London: Routledge.

Chatti, M.A., and M. Jarke. 2007. The future of e-learning: A shift to knowledge networking and social software. International Journal of Knowledge and Learning. 3(4/5): 404-420.

Corbeil, J.R., and M.E. Valdes-Corbeil. 2007. Are you ready of mobile learning. Educause Quarterly 2: 51-58.

Davies, C., and R. Eynon. 2013. Studies of the internet in learning and education: Broadening the disciplinary landscape. In The Oxford handbook of internet studies, ed. W. Dutton. Oxford: Oxford University Press.

Ellison, N.B., and D. Boyd. 2013. Sociality through social network sites. In The Oxford handbook of internet studies, ed. W. Dutton. Oxford: Oxford University Press.

Galloway, A.R. 2012. The interface effect. Cambridge: Polity Press.

Garrison, D.R., and H. Kanuka. 2008. Changing distance education and changing organizational issues. In Economics of distance and online learning: Theory, practice and research, ed. W.J. Bramble, and S. Panda, 13-25. New York: Routledge.

Garrison, R., T. Anderson, and W. Archer. 2000. Critical inquiry in a text-based environment: Computer conferencing in higher education. The Internet and Higher Education 2(2-3): 87-105. 
Gilbert, J., S. Morton, and J. Rowley. 2007. e-Learning: The student experience. British Journal of Educational Technology 38(4): 560-573.

Hamm, S.E., J. Drysdale, and D. Moore. 2014. Towards a mobile learning pedagogy. In Mobile pedagogy and perspectives on teaching and learning, ed. D. McConatha, C. Penny, J. Schugar, and D. Bolton. Hershey, PA: Information Science Reference.

Hodgkin, R.A. 1985. Playing and exploring. London: Methuen.

Kandiko, C.B., and M. Mawer. 2013. Student expectations and perceptions of higher education: Executive summary. London: King's Learning Institute.

Kolodny, N. 2010. Which relationships justify partiality? The case of parents and children. Philosophy \& Public Affairs 38(1): 37-75.

Kreijnsa, K., P. A. Kirschnerb and W. Jochems. 2003. Identifying the pitfalls for social interaction in computer-supported collaborative learning environments: a review of the research. Computers in Human Behavior 19: 335-353.

Laver, J. 1975. Communicative functions of phatic communion. In The organization of behavior in face-toface interaction, ed. A. Kendon, R.M. Harris, and M.R. Key, 215-238. The Hague: Mouton.

Ling, R. 2012. Taken for grantedness: The embedding of mobile communications in society. Cambridge, MA: MIT Press.

Means, B., Y. Toyama, R. Murphy, M. Bakia, and K. Jones. 2010. Evaluation of evidence-based practices in online learning: A meta-analysis and review of online learning studies. U.S. Department of Education, Office of Planning, Evaluation and Policy Development, Washington, DC.

Moore, J.L., C. Dickinson-Deane, and K. Galyen. 2011. e-Learning, online learning and distance learning environments: Are they the same? Internet and Higher Education 14: 129-135.

Oinas-Kukkonen, H., and H. Oinas-Kukkonen. 2013. Humanizing the web: Change and social innovation (technology, work and globalization). E-book: Palgrave MacMillan.

O'Loughlin, A., S.M. Barton, and L. Ngo. 2012. Using mobile technology to enhance teaching. In Handbook of mobile learning, ed. Z.L. Berge, and L. Muilenburg, 293-306. New York: Routledge.

Prensky, M. 2001. Digital natives, digital immigrants. On the Horizon. 9(5): 1-6.

Rideout, V.J., U.G. Foehr, and D.F. Roberts. 2010. Generation m2: Media in the lives of 8-to 18-year-olds. Menlo Park: Kaiser Family Foundation.

Sharpe, R., G. Benfield, G. Roberts, and R. Francis. 2006. The undergraduate experience of blended e-learning: A review of UK literature and practice. York: Higher Education Academy.

Statista. 2015. Number of people purchasing tablet computers in the United Kingdom in 2014. http://www. statista.com/statistics/302868/tablet-computer-purchase-frequency-in-the-uk/. Accessed 28 July 2015.

Stohr, K. 2012. On manners. New York: Routledge.

Thomas, S. 2013. Technobiophilia: Nature and cyberspace. London: Bloomsbury Academic.

Tuckman, B.W. 1965. Developmental sequence in small groups. Psychological Bulletin 63(6): 384-399.

Tuckman, B.W., and M.A. Jensen. 1977. Stages in small group development revisited. Group and Organisation Studies. 2: 419-427.

Wang, V., J. Tucker, and T. Rihll. 2011. On phatic technologies for creating and maintaining human relationships. Technology in Society 33(1): 44-51.

Wang, V., J.V. Tucker, and K. Haines. 2012. Phatic technology in modern society. Technology in Society 34(1): 84-93.

Wouters, C. 2011. How civilizing processes continued: Towards an informalization of manners and a third nature personality. The Sociological Review 59(S1): 140-159.

Wu, J.-H., R.D. Tennyson, and T.-L. Hsia. 2010. A study of student satisfaction in a blended e-learning system environment. Computers \& Education 55: 155-164.

Yuan L., and S. Powell. 2013. MOOCs and open education: Implications for higher education. Bolton: CETISI 